\title{
Education in the Era of COVID-19: Innovative Solutions to Real Challenges
}

\author{
Maharaj-Landaeta Sunita \\ University of Trinidad \& Tobago, Trinidad and Tobago.
}

How to cite this paper: Maharaj-Landaeta Sunita. (2020). Education in the Era of COVID-19: Innovative Solutions to Real Challenges. The Educational Review, USA, 4(11), 193-198.

DOI: 10.26855/er.2020.11.002

Received: October 9, 2020

Accepted: October 31, 2020

Published: November 17, 2020

Corresponding author: Maharaj-Landaeta Sunita, University of Trinidad \& Tobago, Trinidad and Tobago.

Email: sam.aruna32@gmail.com

\begin{abstract}
The COVID-19 outbreak has caused serious concerns to global education systems. Efforts to contain COVID-19 prompted unscheduled closure of schools in over 190 countries worldwide, leaving nearly 1.6 billion learners without concrete alternative schooling options. The study investigates the impact of COVID-19 on education from the lenses of teachers, students and parents. Data was collected through surveys and virtual focus group sessions administered to 150 respondents, from Trinidad \& Tobago, and Venezuelan and Cuban migrants. The results of the qualitative research show that COVID-19 has had adverse effects on education including, learning disruptions, and decreased access to education facilities and teaching and learning resources. The findings also show that the education world has become heavily reliant on technology to ensure continued learning online during the pandemic. However, online education is shown to be hindered by poor infrastructures including, network, power, inaccessibility and unavailability issues, compounded by poor digital skills. The study underscores the damaging effects of COVID-19 on education sector and the need for all educational institutions, educators, and learners to adopt technology, and improve their digital skills in line with the emerging global trends and realities in education.
\end{abstract}

Keywords

COVID-19 Impact on Education, Remote Learning, Infrastructure for digital and blended learning, Education Disruption

\section{Education in the Era of COVID-19}

The COVID-19 pandemic has created one of the largest disruptions of education systems in history (The Economic Times News, 2020), affecting nearly 1.6 billion learners in over 190 countries and all continents. Closure of schools and other physical, brick and mortar, learning spaces has severely impacted education norms globally (UNESCO, 2019).

The crisis is intensifying pre-existing education disparities to continued learning, by diminishing opportunities for the most vulnerable children, youths, and adults, particularly middle and lower income persons, those living in poor, and/or remote areas, and other vulnerable groups such as forcibly displaced persons, migrants, refugees, persons with disabilities and specific needs. Education loss is being threatened to extend beyond this generation and erase years of former progress.

The education disruption owing to the pandemic has had, and will continue having, significant impacts beyond education. School closures impact not only students, teachers, and families, but have far-reaching economic and societal consequences. School closures in response to the pandemic have shed light on various economic and social issues including student debt, barriers to digital learning, food-insecurity and in extreme cases, risk of homelessness. 
Shutdown of educational institutions hampers the provision of essential services to children and communities, including access to nutritious food, deprivation of socialization and psychosocial support. There are real concerns about interrupted learning especially related to parents, teachers and students being unprepared for distance and home schooling. Furthermore, challenges have emerged regarding creating, maintaining, and improving distance learning services (UNESCO, 2019). The new norm affects parents' ability to work as there are gaps in childcare which in turn has an economic impact, as wages are lost. There is the real, increased exposure to violence and exploitation, while diminished opportunities for a stimulating and enriching learning environment and social interaction, places learners at risk of social isolation. Issues on efficient monitoring of attendance, absenteeism and measuring and validating of e-learning options, have also come to the forefront.

The COVID-19 crisis and the unparalleled education disruption are far from over. Many countries have just started re-opening and are in the trial phases of reimagining education and accelerating and adapting changes in teaching and learning to meet existing needs within the COVID context. As mitigation measures, educationalists have adapted shift systems, physical distancing, and hygienic protocols wherever students are being allowed to physically return to school, or alternatively, they are adapting remote modalities of education. Stakeholders however continue to grapple with how to approach the next phase, and furthermore what those phases should include.

Granted, the pandemic and ensuing crisis has stimulated innovation within the education sector. We have seen ground-breaking approaches in support of education and training continuity. However, educational stakeholders have been hurled, head-first into the digital and remote learning sphere. This has posed many hurdles for teachers and learners alike, including, how to become conversant of new and diverse technologies available. There are many considerations in undertaking the challenge of educating persons in the 'new normal' circumstances. The most poignant emerging questions focus on whether current provisions are suitable, sustainable and whether teachers and learners can experience a fulfilling and productive education journey, using current methodologies. There is the question of accessibility to devices and internet services, teachers' capabilities in using the technology efficiently and learners and parents' adaptability to the technology. Furthermore, inherent inequalities in access to tools and technology threaten to deepen the global learning crisis (UNICEF, 2020).

As economic pressures increase, and development support comes under strain, the financing of education could also encounter major challenges, aggravating massive pre-COVID-19 education financing gaps. In the most delicate education systems, the disruption of the school year, as encountered in 2020, will have a disproportionately negative impact on the most vulnerable learners, those for whom the conditions for guaranteeing continuity of learning from home are limited. All these obstacles may compromise the longer-term, holistic development, and futures particularly of those learners from poor and underserved backgrounds.

\subsection{The Trinidad and Tobago Context}

COVID-19 has upended many established systems in Trinidad and Tobago's social, economic, political and education systems, around which the country's existence once functioned. One of the most obvious effects of this upset, however, has been the education system, through which the pandemic has exposed alarming gaps in equity (Mendes-Franco, 2020). In Trinidad and Tobago, conversations have been trending around this issue as underscored in social media discourse, especially following the closures of schools, the trials to facilitate exams in physical spaces and face to face exam preparations, and the realization that blended learning options which included physical attendance to classes, had to be postponed due to the increased numbers of persons contracting the virus.

"To minimize the loss of learning time, emergency remote learning has become the modus-operandi, a response which challenged the most socially vulnerable students" (Kalloo, Mitchell, \& Kamalodeen, 2020). The subsequent launch of online learning management systems (LMS) and rapid, and seemingly loosely planned start to the September 2020 school term via online modalities has provoked varied views and feelings on the efficacy of remote teaching and learning (Dunkley-Malcolm, 2020), and has caused parents, students and teachers to closely analyze weaknesses of the current offerings and ways of improving them.

\subsection{Objectives}

The objective of the research was to amass first-hand information on specific thematic areas and guidance for planning, programming and evaluations related to newly implemented online classes due to COVID-19. This was done by capturing views, feedback and experiences shared directly by teachers, parents, and students in Trinidad \& Tobago. The exercise also contributes to identifying existing capacities and gaps to improve and respond to learners' and teachers' current existing needs and identify where assistance needs to be expanded or redirected.

Responses were collected through surveys, semi-structured remote interviews and virtual focus group sessions which 
were carried out with public and private school teachers, students and parents of locals and migrants from Venezuela and Cuba. These sessions took place between July to mid-September 2020, prompted by the COVID-19 pandemic and its impact on the education system in the country and worldwide. Responses were provided by teachers/lecturers of primary, secondary, and tertiary level educational institutions, and by learners of various ages and grade levels, as well as parents who participated in the research. A total of 150 stakeholders were consulted during the exercise. The researcher utilized the Age, Gender and Diversity approach (Global Protection Cluster, 2020) through consultations with individuals of different ages and backgrounds, such as persons from different geographic and cultural backgrounds, including asylum seekers and individuals with specific needs. This assessment will help identify gaps and pathways related to decision-making, concerning the development of best practices for realistic, efficient and sustainable learning models that can be useful during the COVID-19 era. The study underscores the damaging effects of COVID-19 on education sector and the need for all educational institutions, educators, and learners to adopt technology, and improve their digital skills in line with the emerging global trends and realities in education.

\section{Methodology}

The exercise was conducted through surveys, semi-structured interviews, and virtual focus group discussions (FGDs) with 40 teachers and 60 parents. Separate FGDs were carried out by teachers enlisted to assist with the research. Teachers carried out brief discussion sessions with students in their online sessions, to get a general overview of how students were feeling in the online class sessions. These discussions took place with 50 local and migrant children and youth, ages 10 to 17. Teachers compiled their observations and feedback from their learners and shared this with the researcher. Parents of these learners were briefed prior to the class sessions that these discussions would take place, in order to amass information which could help teachers improve their online teaching methods and way forward. A team of five local Trinidadian education research assistants helped to organize the findings, and they grouped the most poignant points into thematic areas.

The findings presented in this article were based on the views of the stakeholders consulted. The experiences and feedback of participants were analyzed using a systematic and solution-oriented approach, allowing for an overview of experiences faced, as well as identification of capacities and gaps within the Trinbagonian society to enhance educational offerings during the pandemic phase.

\section{Key Findings}

\subsection{The Main Challenges related to Online Learning}

Indeed, distance and online learning has posed many challenges for stakeholders. The following are the key findings of the research:

$>$ One of the main trials identified by educators is limited availability of internet and limited access to devices. While online platforms may be the only way to reach students during lockdown, the digital medium brings its own challenges such as slow internet and connectivity issues which teachers and learners described as disruptive and interfering with the smooth flow of teaching and learning. Conversely, even if power sources and internet connectivity were accessible, some parents expressed the concern that they could not buy tablets, notebooks or laptops for their children to use for online classes. Additionally, even those parents who could afford to purchase these devices expressed concerns, as local stores did not have a variety of device options to offer. The pandemic impacted import of items including technological items. Wherever items could be found, parents complained that the prices of items were hiked up, compared to pre-COVID times.

$>$ Assuming there is reasonable internet access, and learners can access devices the next challenge is the design and development of appealing and relevant content that is appropriate for diverse learning levels and different ages of online learners. Online education was shown to be hindered by poor infrastructures and inaccessibility and unavailability of network, power (electric grid and devices).

$>$ Teachers indicated that online learning is not about dumping a textbook to learners and expecting them to "learn". Materials must be re-versioned, repackaged and adapted to the needs of today's learner audience, ensuring that they capture and maintain the attention and interest of students.

$>$ Additionally, there has been a tendency to adapt online course content and experiences that do not mirror or even resemble the brick and mortar model. This is concerning as learners are expected to apply online learning to physical, day-to-day situations while completing the same/unmodified curriculum and syllabus.

$>$ Poor digital skills were highlighted as an overall concern for mainly parents and teachers.

$>$ Teachers also highlighted that although they were introduced to broad concepts related to distance and online 
learning, they felt the need for more focussed and specialized training sessions, especially related to the use of learning management systems and online teaching tools.

$>$ Parents on the other hand, struggle to keep-up with their children's education, since especially as it relates to younger children, the onus lies on parents to ensure that their children "learn". Some parents explained that many primary-schools teachers email homework to the parents and consider it their responsibility to teach the wards. In some Trinidadian schools, online classes are continuing for approximately 5 to 7 hours, online, five days a week which is also a cause for concern. Outside of the contact hours online, students are sometimes assigned many homework tasks which leaves little room for extra-curricular activities and overall balance and holistic well-being. Some students believed that teachers assigned more homework now, than when they were in physical spaces, to overcompensate for the lack of face to face meetings.

$>$ Teachers who are being monitored by the local ministry of education, have expressed that they feel they are constantly "on call" with the current online learning system. They carry out 5-7 hours of face time via internet, spend many hours correcting assignments received; and to avoid copyright infringements, they must prepare all worksheets from scratch, they have many prohibitions on using text books, even if they are prescribed by the local MOE. These combined with the preparation of workplans and content development was described as time and energy consuming.

$>$ Other difficulties are the availability of lack of infrastructure and funding for devices, data packages and more, for communicating correctly with students and providing methods for excluding cheating in this type of education situation.

$>$ All teachers and parents felt uncertain about the quality and actual levels of learning that was being achieved. Students described discussions as harder to participate in, and teachers found monitoring students online was much more challenging. Also, teachers believed that parents often completed large portions of homework tasks on their children's behalf, and parents admitted to doing this. This of course was not favourable for students learning.

$>$ Eighty percent of parents also admitted to being frustrated having to supervise their children throughout the day. Some indicated that they had a newfound "admiration for teachers", who were very patient and knew how to manage children well.

> Forty-five percent of parents admitted to sometimes having to leave children on their own as they had to go to work. They explained that their supervisors did not understand that they had no caretakers for their children who would usually be at school when they had work. Many had been threatened by supervisors that they might lose their jobs if they did not show up to work. The income they were making however was not enough to hire a caretaker, and furthermore, COVID preventative measures meant that all babysitters, kindergartens, and private facilities were also closed. Parents worried that they were leaving their children unattended and felt wary of associated risks of the lack of supervision.

$>$ Parents and teachers of younger children within the infant aged groups expressed concerns that learners within this age bracket could barely read, hence written instructions were not helpful for online classes. This meant additional assistance and energy was required to tweak instructions verbally, and parents had to be present to help their children navigate classes throughout.

$>$ During the course of the research, it was discovered that some parents were not able to read and write. This brought up the question of if parents do not have the basic preparation to assist how could they be expected to facilitate technical assistance with technology?

\subsection{Recommendations}

It is suggested that the below recommendations be analyzed and studied by the appropriate stakeholders, decision-makers, and persons in authority to ensure the appropriateness of these recommendations and their educational, social and financial impact on all parties:

$>$ The local Ministry of Education in conjunction with relevant health authorities should provide training to school staff in anticipation of the safe reopening of schools and distribution of critical hygiene and COVID-19 prevention items. Furthermore, planning on safe ways to re-open physical classes is essential. This is particularly with a view to ensuring protection, in that learners are fully supervised while parents go to work.

> Parents and students should be provided with awareness sensitization sessions on COVID-19 prevention, hygiene, and physical distancing protocols, as well as, introduction to the new-norms for the eventual re-opening of brick and mortar learning facilities. Examples of such training can be adapted from other countries that are carrying out similar training sessions. See training models being used currently in the Dominican Republic (Hoy Digital, 2020).

$>$ Support for the delivery of education through online platforms and support with community level connectivity for 
under privileged (including connectivity and provision of tablets to underprivileged should be prioritized by government agencies and other authorities).

$>$ Relevant and useful training of teachers to use online platforms, learning management systems and remote teaching tools while schools are closed should be prioritized by decision-makers.

$>$ It is necessary to provide parents/primary caregivers with training to use and assist their children with virtual platforms, as well as, guidance to provide emotional and psychosocial support to their children.

$>$ Remote counselling for teachers, parents and learners to cope with changes such as the lockdowns, isolation and dramatic changes, as well as the new ways of learning is needed.

$>$ It is suggested to evaluate the possibility and viability of providing local and migrant children with internet data packages to support the continuity of online education.

$>$ It is also crucial to strengthen online education via updating the platform to provide offline capability, adapting curriculum and methodological tools to meet the existing cultural and linguistic diversity, as well as reduce barriers of exclusion.

$>$ An important consideration is the special design of online classes to meet the needs of vulnerable and differently abled children.

> It is also important to monitor and estimate the direct and indirect COVID-19 impact on children and young people, including on education, psycho-social well-being and poverty levels.

$>$ All respondents to the research believed it essential to re-think contact hours, content, assignments, evaluations, lesson plans and delivery methods, based on considerations such as age, researched best-practices tried and tested and based on teacher, parent and learners' feedback regarding what they consider to be reasonable, appealing and which promotes positive learning outcomes.

$>$ It is also imperative to consider more appropriate and appealing teaching methodologies based on students learning preferences.

$>$ Re-think evaluation and monitoring methods to determine the true impact of the learning models being offered.

$>$ It is also important to consider more flexible teaching and learning methods which might consider self-paced learning.

\section{Conclusions}

In these unprecedented times in the midst of the COVID-19 crisis, it is critical that the academic educational community learns from these experiences and prioritizes a forward-thinking and practical scholarly approach as solutions to cope with current realities. Reflection and evaluation are imperative to keep improving and positively evolving current education offerings. The COVID-19 epidemic may represent an enduring transformation in the field of education. However, the important thing is to have realistic and useful solutions. Stakeholders including learners, their parents and educators can help document and analyze the effects of current changes to learn and apply new principles and practices to the future. This is not only a time to contribute to the advancement of education in the era of COVID-19, but it may be a seminal moment to contribute to education that could change the world as we know it.

\section{References}

Global Protection Cluster. (2020). Age, Gender, Diversity. Retrieved September 28, 2020, from https://www.globalprotectioncluster. org/themes/age-gender-diversity/.

Hoy Digital. (2020, Sep 28). Retrieved 09 28, 2020, from Así es como el MINERD capacitará desde hoy a maestros en TIC y educación a distancia: https:/hoy.com.do/asi-es-como-el-minerd-capacitara-desde-hoy-a-maestros-en-tic-y-educacion-a-distancia/.

Jascene, D.-M. (2020, Sep 02). New School Term Begins in Trinidad \& Tobago. Retrieved from Caricom Today: https://today.caricom.org/2020/09/02/new-school-terms-begins-in-trinidad-and-tobago/.

Kalloo, R. C., Mitchell, B., \& Kamalodeen, V. J. (2020). Responding to the COVID-19 pandemic in Trinidad and Tobago: challenges and opportunities for teacher education. Journal of Education for Teaching. doi:10.1080/02607476.2020.1800407.

Mendes-Franco, J. (2020, April 16). COVID-19 exacerbates inequalities in Trinidad \& Tobago's education system. Retrieved from GlobalVoices.org: https:/globalvoices.org/2020/04/16/covid-19-exacerbates-inequalities-in-trinidad-tobagos-education- system/202.

The Economic Times News. (2020, August 04). Covid-19 pandemic created largest disruption of education in history, affecting 1.6 billion students: UN. Retrieved September 26, 2020, from Economictimes.indiatimes.com: https://economictimes.indiatimes.com/news/international/world-news/covid-19-pandemic-created-largest-disruption-of-educat ion-in-history-affecting-1-6-billion-students-un-sg-guterres/articleshow/77344094.cms. 
UNESCO. (2019). Adverse consequences of school closures. Retrieved 09 27, 2020, from UNESCO: https://en.unesco.org/ covid19/educationresponse/consequences.

UNICEF. (2020, June 04). Unequal access to remote schooling amid COVID-19 threatens to deepen global learning crisis. Retrieved September 25, 2020, from Unicef.org: https://www.unicef.org/press-releases/unequal-access-remote-schooling -amid-covid-19-threatens-deepen-global-learning. 